\title{
Seleção de áreas de interesse ecológico através de sensoriamento remoto e de otimização matemática: um estudo de caso no município de Cocalinho, MT
}

\author{
Teresa Cristina da Silveira ANACLETO ${ }^{1}$, Anamaria Achtschin FERREIRA ${ }^{2}$, José Alexandre Felizola DINIZ \\ FILHO $^{2}$, Laerte G. FERREIRA ${ }^{3}$
}

\begin{abstract}
RESUMO
A criação de unidades de conservação tem sido a principal estratégia para preservar a biodiversidade. O recente emprego de técnicas como o sensoriamento remoto e a otimização matemática, aliados a dados biológicos, ajudam a definir as áreas prioritárias para conservação, indicando a representação máxima da biodiversidade com base em medidas de complementaridade. O presente trabalho objetivou selecionar áreas de interesse ecológico, com base na heterogeneidade de hábitats, através da integração de imagens de satélite com dados biológicos, em Cocalinho, MT. As 66 parcelas quadradas estabelecidas foram comparadas com base na heterogeneidade e na representatividade mínima (ha) dos ambientes em cada parcela, através do programa SITES. O parque de cerrado é a fitofisionomia predominante em Cocalinho (38,44\%). A região central do município concentrou o maior agrupamento de parcelas, indicando a maior heterogeneidade de hábitats do local. Oficialmente, $6 \%$ da área total do município estão protegidos em duas unidades de conservação na categoria de Refúgios de Vida Silvestre. Esses refúgios foram demarcados em locais com cobertura vegetal homogênea e sem considerar a composição faunística e florística. O modelo usado neste estudo pode ser uma boa abordagem a ser empregada no processo de indicação de novas unidades de conservação no bioma Cerrado ou em outros biomas do Brasil.
\end{abstract}

\section{PALAVRAS-CHAVE}

cerrado, mato grosso, sensoriamento-remoto, modelagem e unidades de conservação.

\section{Selection of areas of ecological importance through remote sensing and matbematics optimization: a case study in the municipality of Cocalinbo, Mato Grosso.}

\begin{abstract}
The creation of conservation areas has been a major strategy for biodiversity conservation. The recent use of techniques such as remote sensing and the optimization of mathematics contribute to the identification of priority areas for conservation through the use of biological data. Thus, maximal representativeness of biodiversity based on measures of complementarity can be achieved. This study aimed to identify areas of ecological importance in the municipality of Cocalinho, Mato Grosso. The selection was based on habitat heterogeneity, through the integration of satellite images and biological information. A total of 66 quadrats (parcels) were established and compared in relation to: 1) habitat heterogeneity, and 2) the minimal representativeness (ha) of vegetation types within each parcel. The analyses were done using the SITES program. The parque de cerrado is the dominant phytophysiognomy in Cocalinho. Parcels were concentrated in the central region of this municipality, indicating its high habitat heterogeneity. Northwards, the landscape is more homogenous due to the dominance of vegetation. In the southern portion, the land occupation is evidence of the expansion of the agriculture frontier in this region. Officially, $6 \%$ of this municipality area is protected in two wildlife refuges. In the SITES selection, these reserves were included only within representativeness of smaller size, when a parcel was attributed as a conservation unit. These reserves were established in areas of homogeneous vegetation cover and were not established taking floristic and faunal data into account. The model used in this study can be a promising approach for indicating conservation areas in Cerrado and in other Brazilian biomes.
\end{abstract}

\section{KEYWORDS \\ Cerrado, Mato Grosso, remote sensing, models, protected areas}

${ }^{1}$ Depto. de Ciências Biológicas, UNEMAT; Nova Xavantina, MT. CEP 78690-000. E-mail: teresacristinaa@yahoo.com

${ }^{2}$ Depto. de Biologia Geral, ICB, UFG; Goiânia, GO. Cx Postal 131 CEP $74001-970$

${ }^{3}$ Depto. de Geografia, IESA, UFG; Goiânia, GO. Cx Postal 131 CEP $74001-970$ 


\section{ACTA AMAZONICA}

SELEÇÃO DE ÁREAS DE INTERESSE ECOLÓGICO ATRAVÉS DE SENSORIAMENTO REMOTO E DE OTIMIZAÇÃO MATEMÁTICA: UM ESTUDO DE CASO NO MUNICÍPIO DE COCALINHO, MT

\section{INTRODUÇÃO}

O bioma Cerrado ocupa uma área de aproximadamente 1,8 milhões de $\mathrm{km}^{2}$, que equivale a $20 \%$ do território brasileiro (Ab' Saber, 1977; Sarmiento, 1983). Dentro de seus limites, encontram-se grandes bacias hidrográficas e alta diversidade de solos, relevos e climas, responsáveis pela sua grande heterogeneidade espacial (Eiten, 1993; Ab' Saber, 1977; Coutinho, 1978). A vegetação dominante é o cerrado sensu lato e o restante são corpos d'água e outros tipos de vegetação como florestas de galerias e campos úmidos (Eiten, 1993). Esse mosaico de hábitats é importante do ponto de vista ambiental, pois além de assegurar a qualidade da água e a integridade do solo, abriga comunidades variadas de animais e plantas, com adaptações para explorar os recursos específicos de cada ambiente (Negret, 1983; Alho, 1993; Silva, 1995).

Ao longo dos últimos 50 anos, o Cerrado vem sendo gradativamente substituído por áreas de pastagem e lavoura, transformando áreas naturais contínuas em manchas isoladas. Essa modificação tem sido considerada um dos maiores problemas ambientais, especialmente nos chamados "países megadiversos" dos trópicos (Mittermeier et al., 1992). Na Amazônia Legal, o Estado de Mato Grosso é o que mais desmata, com registro de $300.000 \mathrm{ha} / \mathrm{ano}$, entre os anos de $1998 \mathrm{e} 2000$ (Primack \& Rodrigues, 1999). Esse ritmo acelerado de destruição é resultado da expansão da monocultura de soja e da pecuária.

A região entre as bacias hidrográficas dos Rios Araguaia e das Mortes é uma das poucas áreas do Estado de Mato Grosso que ainda não foi totalmente transformada pela expansão da fronteira agrícola. Nessa região está localizado o município de Cocalinho que tem como economia principal a pecuária bovina de forma extensiva, baseada em pastagem natural. O inventário realizado na planície de inundação do Rio das Mortes destacou a importância da mastofauna local, através do registro de 48 espécies de mamíferos (Anacleto, 2002). Foram observadas espécies sensíveis à degradação do ambiente, como os carnívoros, que são de topo de cadeia, e espécies pouco conhecidas pela ciência, como o tatu-de-rabo-mole grande (Cabassoustatouay).

Durante os Workshops do Cerrado e da Amazônia (Brasil, 1999 e 2001), Cocalinho teve prioridade para intervenção de ação em curto prazo, com propostas para criação de unidades de conservação, em caráter de extrema importância e categoria de proteção integral e uso sustentável. A partir dessa indicação para conservação, no ano de 2001 foram criados dois Refúgios de Vida Silvestre em Cocalinho, o Corixão da Mata Azul (40.000 ha) e o Quelônios do Araguaia (60.000 ha), ambos inseridos em propriedades particulares. No ano seguinte, com a execução do Projeto de Conservação dos Recursos Naturais de Promoção do Desenvolvimento Sustentável na Região do Araguaia o Estado de Mato Grosso implantou o Parque Estadual do Araguaia (230.000 ha). Aárea do Parque que compreendia o município de Cocalinho foi cedida para o município de Novo Santo Antonio. Esse conjunto de áreas protegidas de Cocalinho foi definido com base em critérios subjetivos, como a elevada riqueza de espécies ou a falta de conhecimento sobre a fauna e a flora.

A criação de unidades de conservação é a principal estratégia adotada pelos governantes para preservar a biodiversidade (Margules \& Pressey, 2000). Em geral, essas unidades têm sido criadas com base em riqueza de espécies, ou aspectos mais gerais de beleza cênica ou para tentar assegurar a proteção de algumas espécies em particular (por exemplo, ameaçadas de extinção ou espécies-bandeira). Entretanto, duas áreas ricas em espécies, por exemplo, podem ter a mesma composição (ou seja, conter exatamente as mesmas espécies), de modo que a seleção de ambas não adiciona mais espécies ao sistema. E por isso que o princípio de complementaridade, que procura aumentar as características das reservas com o mínimo de redundância na definição dessas mesmas características, tem sido proposto como fundamental para a seleção de reservas (Vane-Wright et al., 1991; Pressey et al., 1993). O princípio de complementaridade preconiza que no processo de escolha de áreas adicionais a uma reserva, é melhor escolher áreas que complementem os atributos que se pretende conservar (espécies, hábitats e paisagens entre outros) a duplicar atributos desnecessários. Assim, é preciso ter em mente que os procedimentos de planejamento sistemático em conservação (Margules \& Pressey, 2000) exigem que se defina de forma objetiva o que se deseja preservar (alvos e metas). É possível, por exemplo, que se estabeleça que é necessário proteger várias populações de uma mesma espécie, garantindo assim a manutenção de uma dinâmica regional dessas populações.

O recente emprego de técnicas como o sensoriamento remoto e a otimização matemática, aliados à dados biológicos, ajudam a definir as áreas prioritárias para conservação, alcançando a representação máxima da biodiversidade com o mínimo de custo e utilizando estratégias de complementaridade. O sensoriamento remoto é uma das tecnologias que permite mapear a distribuição geográfica da cobertura vegetal, com base em suas características fisionômicas, ecológicas e florísticas. Essa técnica ganhou impulso considerável, principalmente com a disponibilidade de imagens orbitais que ampliaram as possibilidades de análise, no domínio espectral das propriedades e condições ambientais da cobertura vegetal (Ponzoni, 2001). A otimização matemática é uma técnica que possibilita a análise de múltiplos critérios, combinando, por exemplo, valores de interesse econômico com os de interesse conservacionista.

No presente trabalho utilizou-se uma combinação de técnicas de sensoriamento remoto e otimização matemática, visando estabelecer áreas de interesse ecológico no município de Cocalinho, MT, com base no princípio de complementaridade. A aplicação dessas técnicas permite estabelecer que regiões do município deveriam ser conservadas a fim de maximizar a heterogeneidade de habitats, com um mínimo de área, fornecendo assim um instrumento efetivo para conservação da biodiversidade do Cerrado e respeitando o desenvolvimento de outros aspectos sócio-econômicos no município. 


\section{ACTA AMAZONICA}

SELEÇÃO DE ÁREAS DE INTERESSE ECOLÓGICO ATRAVÉS DE SENSORIAMENTO REMOTO E DE OTIMIZAÇÃO MATEMÁTICA: UM ESTUDO DE CASO NO MUNICÍPIO DE COCALINHO, MT

\section{MATERIAL E MÉTODOS}

\section{Área de estudo}

O trabalho foi baseado em dados de Cocalinho, estado de Mato Grosso. O município é limitado pelas bacias hidrográficas dos Rios das Mortes e Araguaia, entre 14' $23^{\prime} 48^{\prime \prime}$ S e 50 59' 46" W (Figura 1). Ocupa área total de $19.413,88 \mathrm{~km}^{2}$ e possui 5.504 habitantes (IBGE, 2000). A vegetação é característica do bioma Cerrado, com formações florestais, savânicas e campestres. O clima predominante é do tipo Tropical, com duas estações bem marcadas: um período seco (maio a setembro) e um período chuvoso (novembro a março). A precipitação total média anual, com base em dados dos últimos oito anos, é de $1.400 \mathrm{~mm}$ e temperatura média de $25^{\circ} \mathrm{C}$ (dados da Estação Meteorológica de Nova Xavantina, MT).

Para este trabalho, foram utilizadas as cartas topográficas de Cocalinho (SD-22-Z-A-I), Rio Cristalino (SD-22-Y-B-III) e Aruanã (SD-22-Y-B-IV), na escala 1:1000.000, de 1980, do Instituto Brasileiro de Geografia e Estatística (IBGE); o mapa síntese da dinâmica de desmatamento do estado de Mato Grosso, de 1999, elaborado pela Fundação Estadual de Meio Ambiente (FEMA), e as cenas Landsat WRS2 223 68/69/70 e 224 69/70, ETM-EarthSat-Orthorectified, de 2000 e 2001, obtidas através da Global Land Cover Facility, Institute for Advanced Computer

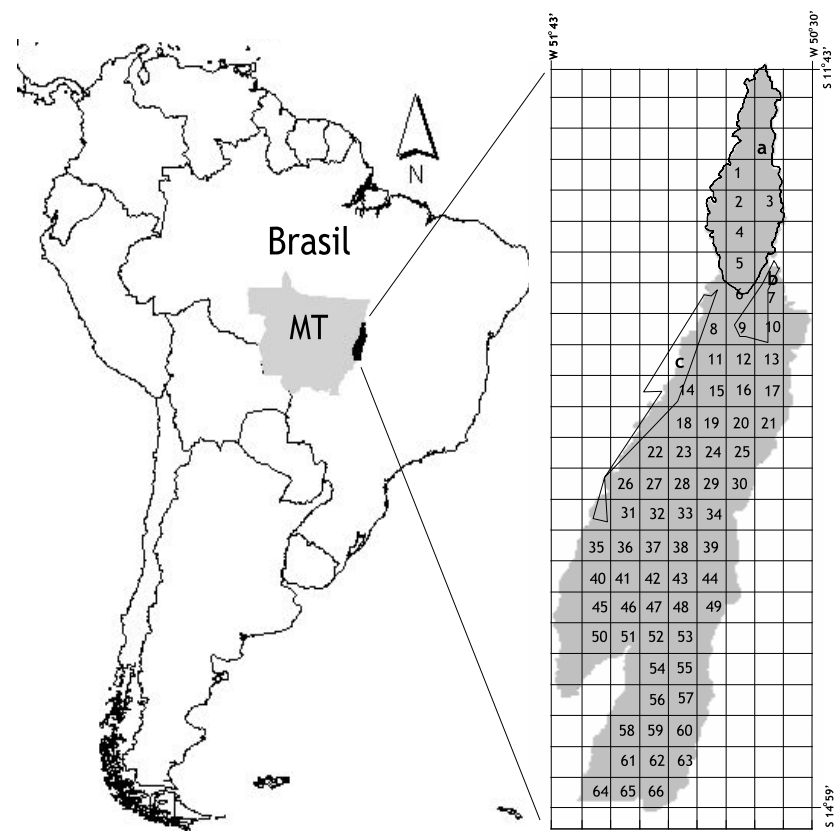

Figura 1 - Localização do município de Cocalinho - MT, Brasil, dividido em 66 parcelas quadradas de $15 \times 15 \mathrm{~km}$. Letras indicam as unidades de conservação: $\mathrm{a}=$ Parque Estadual do Araguaia (área doada a Novo Santo Antonio), b e c $=$ Refúgios de Vida Silvestre Corixão da Mata Azul e Quelônios do Araguaia, respectivamente.
Studies, University of Maryland, College Park (http:// glcfapp.umiacs.umd.edu/index.htm).

As cenas Landsat foram trabalhadas no Programa ENVI (The Environment for Visualizing Images), versão 3.6. A composição das bandas 3, 4 e 5 foi associada ao azul, verde e vermelho, respectivamente. Cada cena foi classificada separadamente, devido à diferença nas datas (ano e sazonalidade), com base em elementos como cor, forma e textura, e em fitofisionomias, que foram identificadas nas imagens a partir de cinco pontos localizados no campo pelo GPS (Global Positioning System). A classificação foi supervisionada e foram estabelecidas 11 classes ambientais naturais e alteradas (Tabela 1). A classificação das fitofisionomias seguiu a proposta de Ribeiro \& Walter (1998). Em seguida, procedeu-se a montagem do mosaico.

Foram estabelecidas 66 parcelas de $15 \times 15 \mathrm{~km}$. Usando o programa SITES versão 1.0, foi aplicado um método matemático para selecionar áreas de interesse ecológico por complementaridade. O SITES dispõe de dois procedimentos para atender o objetivo proposto de conservação: o heurístico rápido e o anelamento simulado. $\mathrm{O}$ heurístico rápido é um procedimento de escolha sequencial que adiciona áreas contendo características mais complementares àquelas das áreas já selecionadas, até que os objetivos previamente propostos tenham sido alcançados. Trata-se de um procedimento rápido com soluções razoáveis, mas nesse processo cumulativo é possível que uma área que atenda muito bem os objetivos propostos talvez nunca seja descoberta (Andelman et al., 1999). $\mathrm{O}$ anelamento simulado procura soluções ótimas (número mínimo de áreas -Andelman et al. 1999), que atendam o objetivo proposto, comparando conjuntos inteiros de áreas. Inicialmente, é selecionado um conjunto aleatório de áreas e a cada iteração esse conjunto é comparado com outras áreas adicionando, excluindo e/ou trocando áreas (Possingham $e t$ al., 2000).

Na presente análise foi utilizada a simulação por anelamento que, por comparar as áreas e não apenas adicioná-las (como acontece no heurístico rápido), tem sido considerada mais eficiente (Possingham et al., 2000; Noss et al., 2002). Esse algoritmo tende a uma solução ótima, minimizando custos ao selecionar a menor área necessária para atingir o objetivo proposto e que esteja mais próxima ou adjacente às reservas existentes no sistema.

Nesta análise, o SITES foi utilizado de acordo com a recomendação mínima padrão de 10 análises e $10^{6}$ iterações por análise (Andelman et al., 1999). As 66 parcelas foram comparadas com base em um objetivo pré-estabelecido, que consistiu em otimizar a representação dos ambientes naturais, alcançando uma meta pré-estabelecida para cada um desses ambientes (oito opções) em um número mínimo de parcelas. Optou-se pela análise através da cobertura vegetal por ser um dado que pode ser avaliado através de sensoriamento remoto, com a confirmação de algumas coordenadas e os respectivos ambientes, registrados no campo. Uma análise mais abrangente, considerando, por exemplo, a diversidade animal seria imprecisa no momento, devido aos escassos dados de Cocalinho serem pontuais e limitados à mastofauna (Anacleto, 
2002). O custo e a prioridade, que são critérios opcionais, foram considerados idênticos em todas as parcelas e não foi estabelecida conectividade entre as parcelas.

Para a seleção das áreas potenciais para conservação por complementaridade foram estabelecidas oito opções de seleção, onde a representatividade mínima (o tamanho de cada ambiente natural) variou de 10.000 até 90.000 ha. Os ambientes alterados, como áreas de pastagem e agricultura, não são importantes para conservação e tiveram representatividade igual a zero, assim o SITES “evita” selecionar parcelas com predomínio desses ambientes. A areia e a água tiveram representatividade mínima de 10 ha nas oito opções.

\section{RESULTADOS E DISCUSSÃO}

Foram quantificadas 11 classes ambientais (Tabela 1). $\mathrm{O}$ parque de cerrado ou campo de murundus é a fitofisionomia predominante em Cocalinho (38,44\%). Formações desse tipo são comuns em planícies inundáveis e, no bioma Cerrado, ocorrem no Pantanal Matogrossense e no Vale do Araguaia. $\mathrm{O}$ solo é hidromórfico com predomínio de herbáceas e presença de murundus, onde se concentram árvores de $2-4 \mathrm{~m}$, arbustos e herbáceas (Ribeiro \& Walter, 1998). Esse tipo de cobertura vegetal, com plantas forrageiras nativas, e a topografia favorecem a atividade predominante do município, a pecuária extensiva. Apesar do avanço dos pastos plantados nos últimos anos, os naturais ainda têm maior expressão espacial em Cocalinho.

As 66 parcelas analisadas $\left(14.850,00 \mathrm{~km}^{2}\right)$ correspondem a 77 \% da área de Cocalinho. Ao estipular a representatividade mínima no processo de seleção das áreas para conservação, $o$ SITES mostra que a exigência de ambientes maiores implica no aumento do número de parcelas (Tabela 2). Isto denota um processo de seleção que não se estabiliza (Figura 2). No entanto, o programa é flexível e possibilita a inserção de outras variáveis, como custos (em termos econômicos) e dados faunísticos (presença/ausência de espécies raras), por exemplo, que poderiam impor limites à seleção de parcelas.
A conectividade entre as parcelas não foi uma variável considerada, mas nas opções estabelecidas, a região central do município concentrou o maior agrupamento de parcelas (Figura 3), indicando a maior heterogeneidade dos ambientes naturais desta região. Ao norte do município, a planície inundável é composta por uma vegetação mais homogênea, dominada por formações campestres que são ocupadas pelo gado no período da seca. Essas áreas são utilizadas como pastagens naturais e queimadas anualmente para aumentar a oferta de alimento.

Tabela 1 - Total e proporção de área dos tipos de ambientes naturais e antropizados classificados a partir das cenas Landsat do Município de Cocalinho, MT.

\begin{tabular}{lll}
\hline \hline Classes ambientais & \multicolumn{2}{c}{ Área } \\
\cline { 2 - 3 } $\begin{array}{l}\text { corpo d'água (com } \\
\text { sedimento) }\end{array}$ & 1,02 & 198 \\
$\begin{array}{l}\text { corpo d'água (sem } \\
\text { sedimento) }\end{array}$ & 0,06 & 12 \\
$\begin{array}{l}\text { areia (margem de } \\
\text { corpo d'água) }\end{array}$ & 0,09 & 17 \\
$\begin{array}{l}\text { parque de cerrado } \\
\text { mata }\end{array}$ & 38,44 & 7.463 \\
$\begin{array}{l}\text { cerrado } \\
\text { campo limpo }\end{array}$ & 14,24 & 2.765 \\
$\begin{array}{l}\text { área alterada I } \\
\text { (agricultura) }\end{array}$ & 12,50 & 2.427 \\
$\begin{array}{l}\text { área alterada II } \\
\text { (cerrado degradado) }\end{array}$ & 6,72 & 2.341 \\
$\begin{array}{l}\text { área alterada III } \\
\text { (pastagem) }\end{array}$ & 7,57 & 1.103 \\
$\begin{array}{l}\text { área alterada IV } \\
\text { (queimada) }\end{array}$ & 1,62 & 1.305 \\
\begin{tabular}{l} 
Total \\
\hline \hline
\end{tabular} & 100,0 & 1.470 \\
\hline
\end{tabular}

Tabela 2 - Opções para seleção de áreas potenciais para conservação, com variação no tamanho dos ambientes naturais (representatividade mínima), maior grupo de parcelas contíguas e área, no município de Cocalinho-MT.

\begin{tabular}{llll}
\hline \hline Opção & $\begin{array}{l}\text { Representatividade } \\
\text { mínima (ha) }\end{array}$ & $\begin{array}{l}\mathbf{N}^{\circ} \text { de parcelas } \\
\text { selecionadas }\end{array}$ & $\begin{array}{l}\text { No e área do maior grupo de } \\
\text { parcelas contíguas (ha) }\end{array}$ \\
\hline 1 & 10.000 & 2 & - \\
2 & 20.000 & 5 & $3(67.500)$ \\
3 & 30.000 & 7 & $3(67.500)$ \\
4 & 50.000 & 14 & $13(292.500)$ \\
5 & 60.000 & 18 & $15(337.500)$ \\
6 & 70.000 & 21 & $16(360.000)$ \\
7 & 80.000 & 24 & $19(427.500)$ \\
8 & 90.000 & 26 & $20(450.000)$ \\
\hline
\end{tabular}




\section{ACTA \\ AMAZONICA}

SELEÇÃO DE ÁREAS DE INTERESSE ECOLÓGICO ATRAVÉS DE SENSORIAMENTO REMOTO E DE OTIMIZAÇÃO MATEMÁTICA: UM ESTUDO DE CASO NO MUNICÍPIO DE COCALINHO, MT

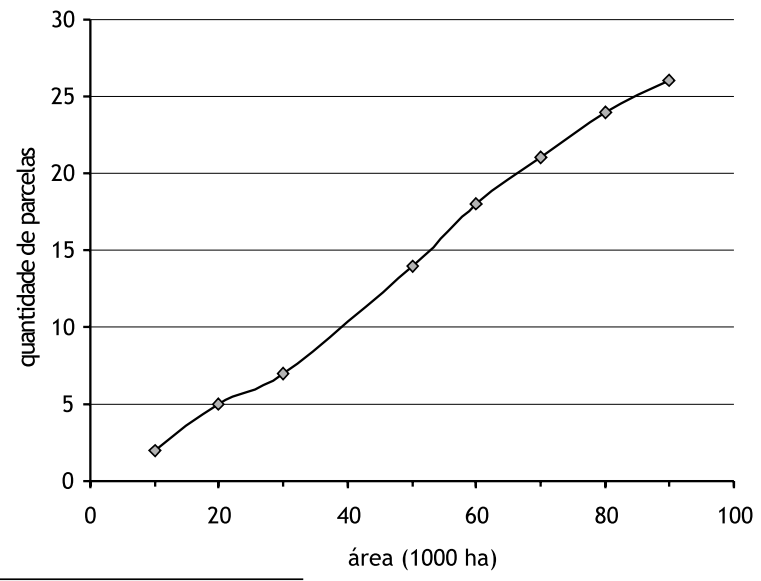

Figura 2 - Representatividade mínima (ha) de quatro ambientes naturais e a quantidade de parcelas abrangidas, para a simulação de seleção de áreas de interesse ecológico, em Cocalinho,MT.

Na região central de Cocalinho há importantes cursos d'água como o Ribeirão Água Preta, o Rio Cristalino e o Rio Forquilha, entre outros. É possível que o agrupamento tenha se formado em razão das parcelas selecionadas abrangerem cursos d'água, que em algumas propriedades ainda são mantidas como áreas de preservação permanente (vegetação nativa situada ao longo de qualquer curso d'água) e/ou áreas de reserva legal (vegetação nativa que represente um mínimo percentual da área da propriedade rural) em cumprimento da Lei Complementar $n$. 38 art.62 - Código Estadual do Meio Ambiente.

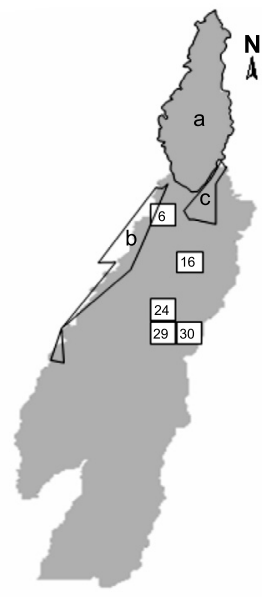

20.000ha

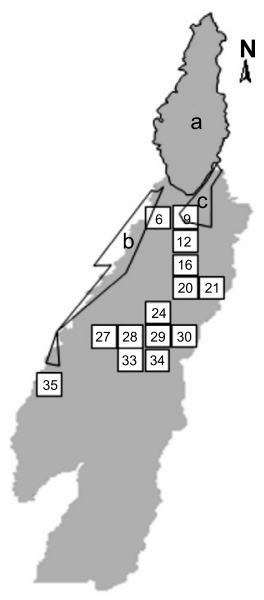

$50.000 \mathrm{ha}$

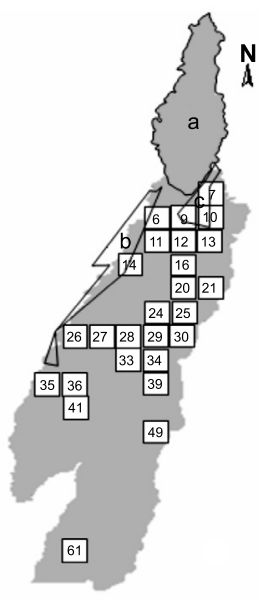

90.000 ha
Figura 3 - Comparação das parcelas selecionadas de acordo com a representatividade mínima (ha) de quatro ambientes naturais (parque de cerrado, mata, cerrado e campo limpo) do município de Cocalinho, MT. Letras indicam as unidades de conservação: $\mathrm{a}=$ Parque Estadual do Araguaia, b e c $=$ Refúgios de Vida Silvestre Quelônios do Araguaia e Corixão da Mata Azul, respectivamente.
Apesar dos fatores antrópicos, como a pecuária extensiva e a agricultura insipiente, a baixa densidade populacional registrada no centro e no norte de Cocalinho favorece a conservação dos ecossistemas naturais, pois a destruição ambiental tende a ocorrer em locais de alta densidade humana (Fearnside, 1986)

Ao sul, o uso e a ocupação do solo são evidências da expansão da fronteira agrícola. Nessa área, a agricultura divide o espaço produtivo com a pecuária e há concentração da população rural, que representa $65 \%$ dos habitantes de Cocalinho. Diferente do centro e do norte do município, a infra-estrutura viária é boa, com grandes balsas e uma ponte de concreto armado com cerca de $200 \mathrm{~m}$ de vão sobre o Rio Araguaia. O fácil acesso dessa região com outros municípios de Mato Grosso e Goiás explica o favorecimento da exploração econômica e a degradação dos recursos naturais. Esse acesso ainda favorece a pesca predatória e o turismo desordenado às praias que se formam no período de julho a setembro, nas margens dos Rios das Mortes e Araguaia. O impacto causado principalmente pela pecuária e pelo turismo desordenado pode constituir um vetor de contaminação hídrica e comprometer as áreas ainda preservadas de Cocalinho.

Cocalinho é indicado como área prioritária para a criação de unidades de conservação de proteção integral, por estar inserido na região que contém as planícies inundáveis entre o Rio Araguaia e o Rio das Mortes (Brasil, 1999 e 2001). Em 2001, o extremo norte do município, passou a integrar o Parque Estadual do Araguaia, cuja área foi doada ao município de Novo Santo Antonio. Assim, Cocalinho doou $2.675,05 \mathrm{~km}^{2} \mathrm{da}$ área original e sua área atual compreende $16.538,83 \mathrm{~km}^{2}$ (Setor de Zoneamento do Estado de Mato Grosso-Cuiabá, MT). Oficialmente, $6 \%$ da área total do município estão protegidos através da criação de duas unidades de conservação estaduais, os Refúgios de Vida Silvestre (RVS) do Corixão da Mata Azul e Quelônios do Araguaia. Esses refúgios constituem áreas de proteção integral e visam assegurar condições para a existência ou a reprodução de espécies ou comunidades da flora local, bem como de fauna residente ou migratória (Decreto Estadual 1795, 04/11/1997).

Dentre as 66 parcelas estabelecidas, duas (8 e 14) cortam o RVS Quelônios do Araguaia e quatro (6, 7,9 e 10) cortam o RVS Corixão da Mata Azul (Fig. 1). Na seleção do SITES, os RVS foram incluídos nas simulações onde o tamanho dos ambientes naturais ficou acima de 60.000 ha, exceto para a parcela 8, que aparece a partir de 20.000 ha e a 6 , que não aparece nas simulações. Os RVS somente foram incluídos em representatividades de menor tamanho, quando foi atribuído status de unidade de conservação para as seis parcelas. Embora os refúgios estejam nos limites da área de estudo, observa-se que foram demarcados em locais com cobertura vegetal homogênea, onde predomina o parque de cerrado. Esses refúgios provavelmente não abrigam uma fauna representativa do bioma Cerrado e são preferidos para a exploração pecuária. Além disso, nesses locais não há uma equipe em condições de proceder a fiscalização constante e, como os refúgios compreendem propriedades particulares, alguns latifundiários 
continuam desmatando e impedindo até o acesso de pesquisador devidamente autorizado pela FEMA. As áreas dos RVS só se tornarão públicas se forem adquiridas através do Sistema de Compensação de Reserva Legal (Lei Estadual MT $7868,20 / 12 / 2002$ ).

As áreas aqui indicadas embasaram-se somente nas características fitofisionômicas de Cocalinho. Quando dados biológicos e físicos da região central forem acrescentados, a avaliação será mais precisa. Para o presente trabalho, cuja análise contou com as poucas variáveis disponíveis, a opção de 50.000 ha é a mais adequada porque, dentre as opções estabelecidas de representatividade mínima, é a menor área com maior quantidade de parcelas contíguas, abrange uma área heterogênea, com baixa densidade humana e atende a necessidade de preservar macro-hábitats. Muitas espécies, como as populações de grandes mamíferos, não persistem em fragmentos pequenos (Turner \& Corlett, 1996). A perda de grandes predadores pode desestabilizar as populações dos predadores de sementes e isto pode afetar as espécies arbóreas de uma floresta (Terborgh, 1992). Portanto, é preciso realizar pesquisas mais refinadas sobre a integridade dos ambientes aqui analisados, a conectividade existente entre os fragmentos das parcelas e a complementaridade desses fragmentos. Com base nesses dados será possível selecionar, de forma mais precisa, as áreas adequadas à criação de unidades de conservação.

A opção de 50.000 ha também satisfaz as exigências legais. Segundo a legislação estadual (Lei Complementar n. 38 Art 62 $\S 2^{\circ}$ ), as áreas de cerrado devem manter o percentual mínimo de $20 \%$ por propriedade. Admitindo esse percentual para a área total analisada neste trabalho $\left(14.850 \mathrm{~km}^{2}\right)$, as 13 parcelas agrupadas estariam protegendo $19,6 \%$.

Segundo Margules \& Pressey (2000), na prática, as áreas escolhidas para conservação estão normalmente localizadas em lugares que não maximizam a representatidade da biodiversidade, sendo que a exploração econômica compete com as melhores áreas. De fato, a criação e a manutenção de unidades de conservação é um processo que encontra resistência no setor político-social e econômico. Há governantes, principalmente em países de terceiro mundo, que priorizam a implantação de empresas, geralmente poluidoras, que geram empregos à população e pagam impostos. A aquisição e o manejo de áreas protegidas em botspots é um processo oneroso, o custo é de aproximadamente US $\$ 10 /$ ha e em áreas mais populosas o preço da terra é mais elevado (Stuart et al., 2001).

O estado de Mato Grosso, a partir dos anos 70, foi considerado área preferencial para a implantação de projetos de colonização privada no país e, ainda hoje, sua realidade econômica dificulta a aquisição de áreas para conservação ambiental. Outra dificuldade está na escassez dos recursos públicos, que compromete a implementação (manutenção e fiscalização adequada) das unidades de conservação já criadas, bem como os processos que envolvem a criação de novas unidades de conservação. Existem alternativas para contornar parcialmente esses problemas, como a criação de áreas protegidas em propriedades particulares, por exemplo, e cada caso deve ser analisado separadamente, de acordo com as prioridades de preservação. No Mato Grosso, algumas áreas estão protegidas através do estabelecimento de unidades de conservação de uso sustentável, como as Reservas Particulares do Patrimônio Natural - RPPN (SNUC, Lei n ${ }^{\circ}$ 9.985, 18/07/2000) e do Sistema de Compensação de Reserva Legal. Nesse tipo de unidade de conservação é permitido desenvolver atividades de turismo ecológico, lazer e educação ambiental, gerando opções de renda para o proprietário. No sistema de compensação, o proprietário que apresentar propriedade com percentuais de reserva legal menores que os estabelecidos pela legislação (Código Estadual do Meio Ambiente, art. 62 da Lei Complementar no 38, 21/11/1995 e Código Florestal), deve, entre outras opções, compensar a reserva legal por outra área equivalente em importância ecológica e extensão; através de alienação gratuita ao patrimônio público estadual, de áreas situadas dentro das Unidades de Conservação Estaduais de proteção integral, desde que estejam localizadas nos limites de Mato Grosso. Dentro das opções legais existentes, é imprescindível incentivar projetos que promovam o estabelecimento de RPPN e outras unidades de conservação de uso sustentável, proceder ao censo dos proprietários e as respectivas áreas que devem participar do processo de compensação e exigir o cumprimento da lei.

Os dados aqui apresentados indicam que a associação entre as técnicas de sensoriamento remoto e os métodos de otimização, proporciona um bom direcionamento no processo de seleção de áreas para conservação do Cerrado. Os resultados desse estudo, em conjunto com os dispositivos legais existentes, pode auxiliar no processo de indicação de áreas potenciais para o estabelecimento de novas unidades de conservação, envolvendo também estudos sistemáticos de planejamento que abordem estrutura fundiária, interesses sócio-econômicos, tamanho das áreas, conectividade, replicação e escolha de espécies-alvo.

\section{AGRADECIMENTOS}

Às pessoas que auxiliaram na elaboração desse trabalho, especialmente a Manoel E. Ferreira, Nilson C. Ferreira, Adriana A. Silva, Simone A. Jácomo, Miriam P. Pinto, Zenón G. N. Del Prado (todos da UFG-GO), Darius Tubelis (Australian National University, Canberra) e dois revisores anônimos. Teresa Cristina S. Anacleto agradece a CAPES pelo apoio financeiro e a UNEMAT pelo apoio à qualificação profissional.

\section{BIBLIOGRAFIA CITADA}

Ab'Sáber, A.N. 1977. Espaços ocupados pela expansão dos climas secos na América do Sul, por ocasião dos períodos glaciais quaternários. Paleoclimas, 3:1-18

Alho, C.J.R. 1993. Distribuição da fauna num gradiente de recursos em mosaico. In: Novaes Pinto, M. (Org.). Cerrado. $2^{\circ}$ ed. Editora Universidade de Brasília. Brasília, DF. p.213262 . 


\section{ACTA \\ AMAZONICA}

SELEÇÃO DE ÁREAS DE INTERESSE ECOLÓGICO ATRAVÉS DE SENSORIAMENTO REMOTO E DE OTIMIZAÇÃO MATEMÁTICA: UM ESTUDO DE CASO NO MUNICÍPIO DE COCALINHO, MT
Anacleto, T.C.S. 2002. Levantamento da mastofauna do Pantanal Mortes-Araguaia. In: Relatório Técnico CNPQ/PNOPG Programa Norte de Pesquisa e Pós-Graduação, Processo 520345/99. Projeto - Estudo preliminar do ecossistema Pantanal Mortes-Araguaia. Brasília, DF. p.8-12.

Andelman, S.J.; Ball, I.; Davis, F.W.; Stoms, D.M. 1999. SITES V.1.0, an analytic toolbox for ecoregional conservation portfolios. Technical report, The Nature Conservancy. http:/ /www.biogeog.ucsb.edu/projects/tnc/toolbox.html. Acessado em 24/04/2004.

Brasil. 1999. Ações prioritárias para a conservação da biodiversidade do Cerrado e Pantanal. Ministério do Meio Ambiente, FUNATURA, Conservation International, Fundação Biodiversitas, Universidade de Brasília. Brasília, DF. 22 p.

Brasil, 2001 - Avaliação e identificação de ações prioritárias para a conservação, utilização sustentável e repartição dos benefícios da biodiversidade na Amazônia brasileira. Ministério do Meio Ambiente, Instituto Socioambiental ISA, Instituto de Pesquisas Ambientais da Amazônia - IPAM, Grupo de Trabalho Amazônico - GTA, Instituto Sociedade, População e Natureza - ISPN, Instituto do Homem e do Meio Ambiente da Amazônia - IMAZON e Conservation International do Brasil. Brasília, DF. http:// www.socioambiental.org/website/bio/index.htm. Acessado em 24/04/2004.

Coutinho, L.M. 1978. Aspectos ecológicos do fogo no cerrado. VI - A época das queimadas e floração de espécies do estrato herbáceo subarbustivo. Ciência e Cultura, 30:416

Eiten, G. 1993. Vegetação do Cerrado. In: Novaes Pinto, M. (Org.). Cerrado. $2^{\circ}$ ed. Editora Universidade de Brasília, DF. p.17-73.

Fearnside, P.M. 1986. Spatial concentration of deforestation in the Brazilian Amazon. Ambio, 15(2):74-81

IBGE, 2000. Instituto Brasileiro de Geografia e Estatística. Censo Cidades. http://www.ibge.gov.br. Acessado em 15/01/2004.

Margules, C.R.; Pressey, R.L. 2000. Systematic conservation planning. Nature, 405:243-253

Mittermeier, R.A.; Werner, T.; Ayres, J.M.; Fonseca, G.A.B. 1992. O país da megadiversidade. Ciência Hoje, 14 (81):20-27

Negret, A. J. 1983. Diversidade e abundância da avifauna da Reserva Ecológica do IBGE, Brasília-DF. Dissertação de Mestrado, Universidade de Brasília. Brasília, DF. 136p.
Noss, R.; Carrol, C.; Vance-Borland, K.; Wuethener G. 2002. A multicriteria assessment of the irreplaceability and vulnerability of sites in the greater Yellowstone ecosystem. Conservation Biology, 16(4):895-900

Ponzoni, F.J. 2001. Comportamento espectral da vegetação. In: Menezes, P. R.; Madeira Netto, J. S. (Eds.). Sensoriamento Remoto reflectância dos alvos naturais. Ed. Universidade de Brasília, Embrapa Cerrados. Brasília,DF. p.157-189.

Possingham, H.P.; Ball, I.R.; Andelman, S. 2000. Mathematical methods for identifying representative reserve networks. In: Ferson, S.; Burgman, M. (Eds.). Quantitative methods for conservation biology. Springer-Verlag, New York. p.291306.

Pressey, R.L.; Humphries, C.J.; Margules, C.R.; Vane-Wright, R.I.; Williams P.H. 1993. Beyond opportunism: key principles for systematic reserve selection. Tree, 8(4):124-128

Primack, R.B.; Rodrigues, E. 1999. Biologia da Conservação. Londrina, PR. 328p.

Ribeiro, J.F.; Walter, B.M. T. 1998. Fitofisionomias do bioma cerrado. In: Sano, S.M.; Almeida, S.P. (Eds.). Cerrado ambiente e flora. EMBRAPA/CPAC. Planaltina, DF. p.89-152.

Sarmiento, G. 1983. The savannas of tropical America. In: Bourlière, F. (Ed.). Ecosystems of the world 13: tropical savannas. Elsevier Scientific Publ. Co, New York. p.245288.

Silva, J.M.C. 1995. Birds of the cerrado region, South América. Steenstrupia, 21:69-92

Stuart, L.P.; Ayres, M.; Balmford, A. 2001. Can we defy nature's end? Science, 293:2207-2208

Terborgh, J. 1992. Maintenance of diversity in tropical forests. Biotropica, 24:283-292

Turner, I.M.; Corlett, R.T. 1996. The conservation value of small, isolated fragments of lowland tropical rain forest. Tree, 11:330-332

Vane-Wright, R.I.; Humphries, C.J.; Williams, P.H. 1991. What to protect? systematics and the agony of choice. Biological Conservation, 55:235-54
RECEBIDO EM 09/12/2004
ACEITO EM 17/11/2005 
